\title{
Metabolic and Inflammatory Cerebral Diseases: Electrophysiological Aspects
}

\author{
G.B. Young
}

\begin{abstract}
The electroencephalogram (EEG) is an important diagnostic tool in coma. Although comatose patients may be similar on neurological examination, the EEG reveals a wide range of abnormalities. For metabolic and septic encephalopathies, the "anesthesia model" is a useful analogy. The EEG is very sensitive to the depth or severity of brain dysfunction in coma as well as the direction of the process if serial tracings or continuous recordings are used. While the EEG is rarely specific for the etiology of coma, it may help determine the class or general category of disease process. In conditions capable of causing neuronal death, e.g., anoxia-ischemia, the EEG can be of prognostic value.
\end{abstract}

\begin{abstract}
RÉSUMÉ: Maladies cérébrales métaboliques et inflammatoires: aspects électrophysiologiques. L'EEG est un outil diagnostique important dans le coma. Même si l'examen neurologique de patients comateux se ressemble, l'EEG révèle une grande variété d'anomalies. Dans les encéphalopathies métaboliques et septiques, le "modèle de l'anesthésie" est une analogie utile. L'EEG est très sensible à la profondeur ou à la sévérité de la dysfonction cérébrale dans le coma ainsi qu'à la direction du processus si des tracés en série ou un enregistrement continu sont utilisés. Bien que l'EEG est rarement spécifique de létiologie du coma, il peut aider à déterminer la classe ou la catégorie générale du processus morbide. Dans les conditions capables de causer la mort neuronale, c'est à dire l'anoxie-ischémie, l'EEG peut avoir une valeur pronostique.
\end{abstract}

Can. J. Neurol. Sci. 1998; 25: S16-S20

\section{The ANesthesia Model}

Anesthesia and metabolic encephalopathies share a number of features: EEG patterns show similarities; the graded EEG response to increasing anesthetic administration is similar to the evolutionary changes seen with increasing severity of metabolic or toxic derangement; and, with some clinical exceptions, the changes are reversible.

In such a model the anesthetic dose, like the severity of encephalopathy, shows an inverse relationship with EEG frequency and a direct relationship with amplitude.' Such slowing accompanies decreased unitary activity of cerebral cortical neurons. ${ }^{2}$ This linearity breaks down at high doses with the appearance of burst-suppression pattern or epileptiform activity. The following incremental changes are common to anesthesia and most metabolic encephalopathies: 1) Desynchronization, followed by theta; 2) Increase in rhythmicity and voltage of delta, initially mixed with faster frequencies; 3) Simplified delta (without faster frequencies); 4) Burst-suppression - with duration of suppression becoming longer with deeper levels; 5) Suppression - isoelectric EEG.

Examples of these patterns are given in Figures 1 to 5 .

This progression applies to sedative type drug intoxications, most metabolic encephalopathies, e.g., hepatic and renal failure, septic encephalopathy, carbon dioxide narcosis and adrenal failure. $^{3}$ There are, however, limitations and imperfections of this analogy: 1) With some clinical conditions capable of causing neuronal death, such as anoxic-ischemic encephalopathy, the EEG changes are not reversible, and may progress, if severe enough, to permanent suppression. 2) In some diseases specific features are superimposed on the patterns of sinusoidal waves or suppression, e.g., triphasic waves in hepatic encephalopathy, renal failure and septic encephalopathy, and spikes in anoxia and penicillin encephalopathy. 3) The number of metabolic encephalopathies that progress to a burst-suppression or suppression pattern are limited. Examples of the latter include: anoxicischemic encephalopathy, septic encephalopathy, drug-induced coma (especially from barbiturates and benzodiazepines), hypothermia, and extreme hypoglycemic encephalopathy. ${ }^{4-7}$ Most others do not progress to this degree of abnormality unless the encephalopathy is associated with raised intracranial pressure and resultant global ischemia, as in the cerebral edema accompanying acute hepatic encephalopathy or Reye's syndrome..$^{3.8}$

Age has a bearing on EEG phenomena in coma. Triphasic waves are not found in children, while 14 and 6 positive spikes in the posterior head have been described in comatose children with Reye's syndrome or hepatic encephalopathy. ${ }^{9}$

From the Department of Clinical Neurological Sciences, The London Health Sciences Centre, London, Ontario.

Reprint requests to: G.B. Young, Department of Clinical Neurological Sciences, London Health Sciences Centre, 375 South Street, London, Ontario, Canada N6A 4G5 


AWAKE
$F_{P_{1}}-F_{3}$
$F_{3}-C_{3}$
$C_{3}-P_{3}$

Figure 1: The EEG is dominated by theta $(>4$ but $<8 \mathrm{~Hz})$ frequencies in this 67-year-old man who was awake but confused with a mild metabolic encephalopathy.

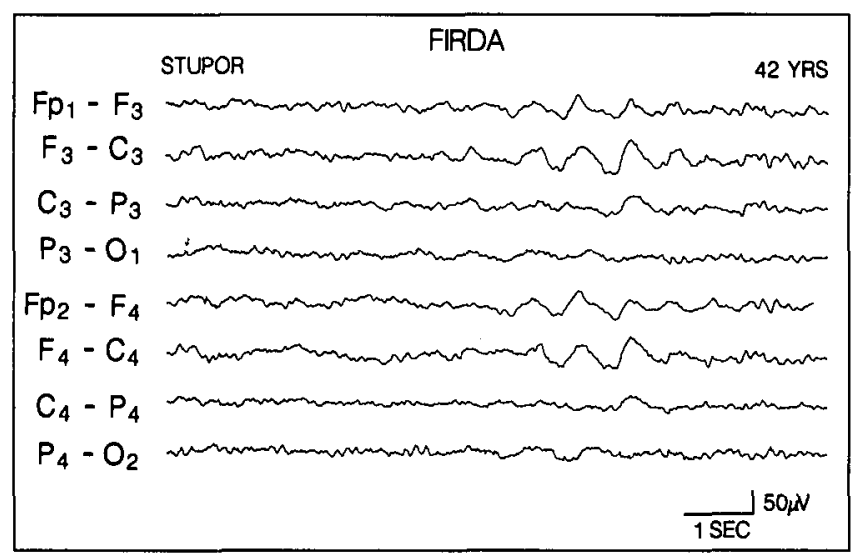

Figure 2: A more obtunded, stuporous, patient with a metabolic encephalopathy shows runs of frontal intermittent rhythmic delta activity (FIRDA) against a slow background.

\section{CNS INFLAMMATION}

Bacterial and tuberculous meningitis usually produce irregular, widespread delta as the predominant abnormality. ${ }^{10}$ Background activity is usually better preserved than in encephalitis. The improvement in frequencies parallels clinical resolution." In patients with a good prognosis, the EEG shows rapid normalization within 6-9 days. ${ }^{5}$ Prolongation of EEG abnormalities beyond two weeks suggests a complication such as infarction from vasculitis, hydrocephalus or subdural hygromas (the latter in young children).

Encephalitis also usually produces delta as the predominant abnormality. ${ }^{12}$ Multifocal epileptiform activity commonly occurs, reflecting cortical grey matter disease. ${ }^{13}$ In herpes simplex encephalitis, one or both temporal regions is/are the site of maximal slowing and between the second and fourteenth day of illness may contain PLEDs (periodic lateralized epileptiform discharges) with a repetition rate of $0.5-2$ per second. ${ }^{14,15}$ This feature is important as herpes simplex encephalitis is treatable with the anti-viral agent

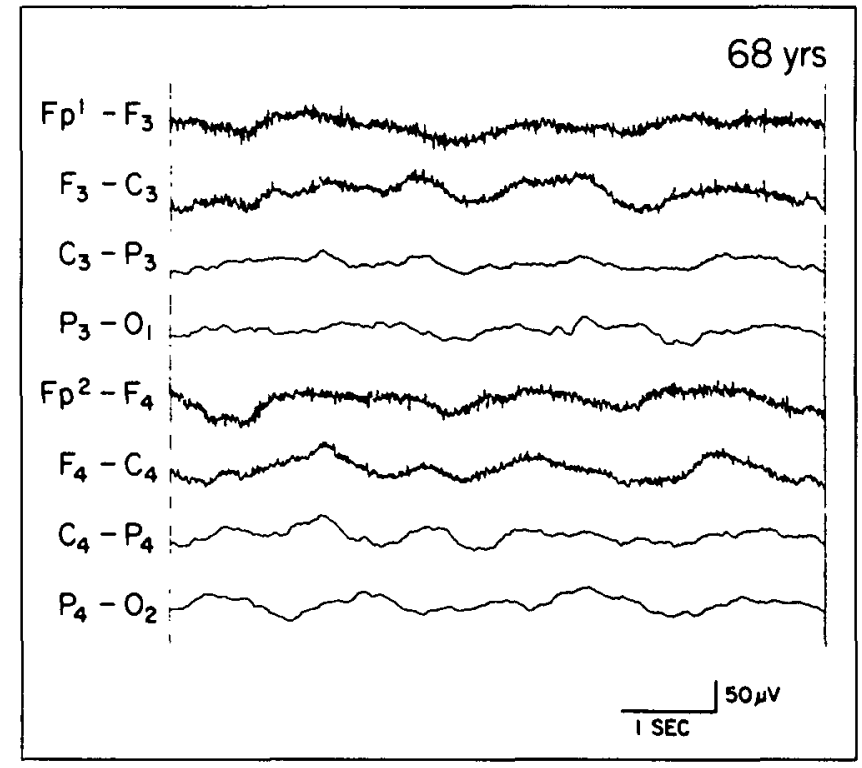

Figure 3: A comatose patient with a severe septic encephalopathy shows high voltage, very slow frequencies as the predominant rhythm.

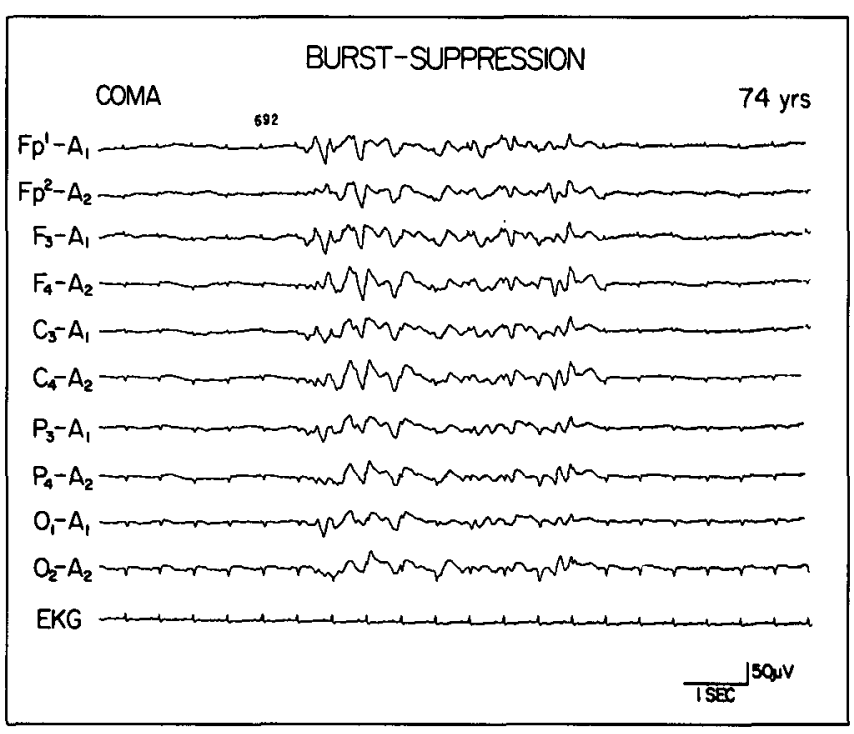

Figure 4: A 74-year-old woman has a generalized burst-suppression pattern after suffering a cardiac arrest. The periods of suppression contain only electrocardiographic (EKG) artifact.

acyclovir. ${ }^{16}$ Multifocal delta may accompany acute disseminated encephalomyelitis, a post-infectious immunologically mediated syndrome which is characterized by perivenous demyelination. ${ }^{7}$

Septic encephalopathy, in which the brain appears to be affected in an indirect, reversible fashion (at least in the early, acute stage) behaves like most metabolic encephalopathies and closely follows the "anesthetic model". ${ }^{17}$

\section{REACTIVITY, COMPLEXITY AND VARIABILITY}

Reactivity, or responsiveness of the EEG to stimuli, is one of the best indices of brain functional integrity (see Figure 6.) Although reactivity is not assessed during anesthesia, it has a 


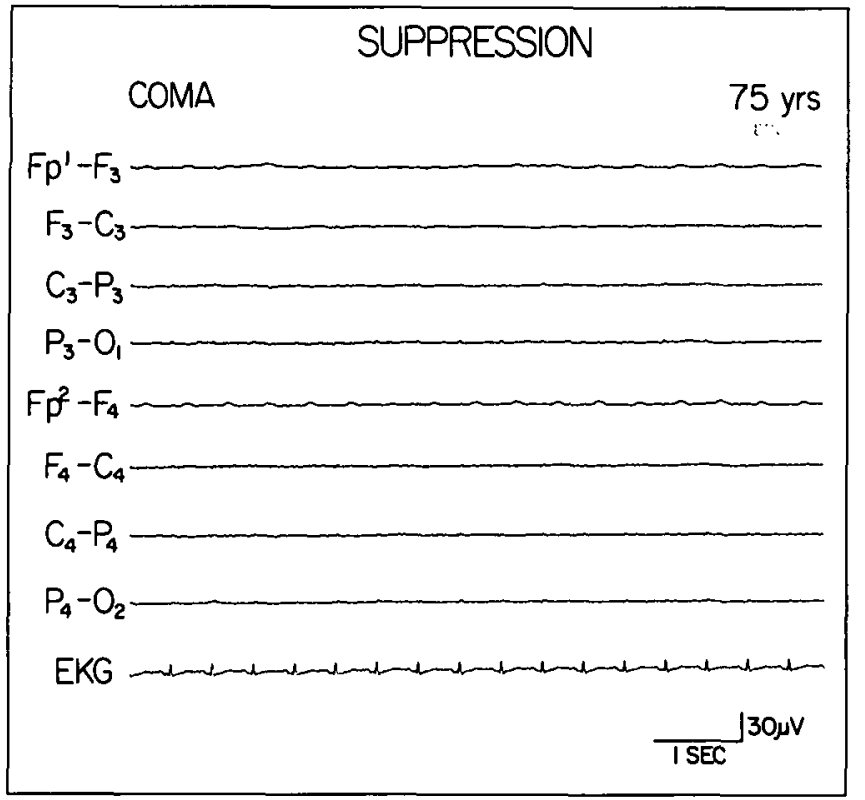

Figure 5: A 75-year-old man has a completely suppressed EEG after a cardiac arrest. Minimal EKG artifact is seen.

practical value in states of decreased consciousness. ${ }^{18}$ In general, reactivity, seen in lighter stages of coma, is inconsistently associated with clinical arousability. Reactivity may consist of an increase in amplitude, frequency, or even slowing often as bisynchronous rhythmic delta activity or a decrease in amplitude of background rhythms. In general, such EEG responsiveness is associated with a greater chance of recovery or survival than lack of reactivity. ${ }^{12}$ Reactivity to sound, painful somatic stimuli and passive eye opening should be tested in all comatose patients, unless contraindicated because of raised intracranial pressure.

Variability of patterns or alternating patterns, the appearance of mixtures of frequencies and the increase in voltage of faster frequencies are all associated with a better prognosis in coma than the absence of these features. ${ }^{19,20}$

\section{Prognosis}

In contributing to prognosis, the EEG must be integrated with other factors including etiology (as it relates to the capacity to cause irreversible damage), duration of the illness, the severity of impairment of cerebral function (the degree of arousability and presence or absence of purposeful responses), brainstem integrity (particularly the state of brainstem reflexes and respiration) and the severity and reversibility of impairment of other organs. ${ }^{21}$ The EEG alone is not prognostically definitive in metabolic, toxic or septic conditions that are not due to neuronal death as: 1) the neuronal dysfunction is potentially reversible, much like an anesthetic, and 2) the outcome is dependent on other variables that must be taken into consideration, including age, nature of the underlying illnesses, degree and reversibility of multiorgan failure. When neuronal death is a definite possibility, as in anoxic-ischemic encephalopathy after cardiac arrest, the EEG is often definitive. For example, complete suppression or electrocerebral silence shows a strong association with severe, irreversible cerebral cortical damage that is not compati-

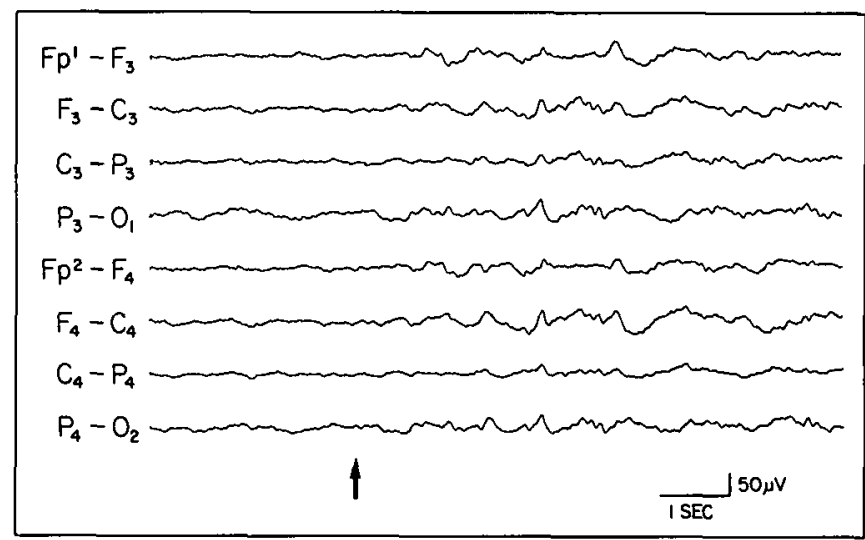

Figure 6: Reactivity is shown with increased voltage of rhythms with a predominance of slow frequencies after a sound stimulus (arrow).

ble with an outcome better than a persistent vegetative state. ${ }^{21}$ Other patterns, e.g., alpha coma or a burst-suppression pattern, are usually, but not invariably, associated with a poor outcome after cardiac arrest. However, serial or continuous EEGs show evolutionary changes that are very helpful prognostically. For example, the transition of an alpha pattern coma, several days later, to a burst-suppression pattern without reactivity is associated with a poor outcome, while the development of continuous, but variable and reactive rhythms, indicates a favorable prognosis. ${ }^{22}$ After cardiac arrest, a burst-suppression with generalized epileptiform discharges in the bursts, with a worsening picture over days, is rarely, if ever followed by recovery of conscious awareness. ${ }^{23}$

Several scoring systems for grading the severity of EEG abnormalities have been developed for anoxic, traumatic and septic encephalopathies and Reye's syndrome..$^{11.24-28}$ We have developed a scoring system that has a high degree of inter-rater reliability while capturing all the essential patterns encountered in patients with impaired consciousness (see Table). In attempting to determine the prognosis, however, it is best to relate the EEG into the entire clinical picture and to consider whether potentially reversible factors are operative. ${ }^{29}$ The less ambiguous the categories, the better the inter- and intra-rater reliability. ${ }^{15}$

\section{EXTENSIONS OF EEG IN COMA}

Continuous EEG (CEEG) monitoring in the intensive care unit is being explored. CEEG might best be applied to cases in which the patient is in coma with a condition which is potentially unstable but potentially treatable and reversible. Changes in frequency and amplitude, focal features or epileptiform activity have diagnostic and therapeutic implications and could influence management and outcome. CEEG facilitates the monitoring of anesthesia achieved with barbiturates (used in the treatment of status epilepticus) or sedation with opiates or benzodiazepines. CEEG may be also useful in cases in which the patient's central nervous system cannot be assessed clinically e.g., patients on neuromuscular blocking agents. "Quantitative EEG", such as power spectral analysis, allows objective trending of amplitudes and frequencies. ${ }^{30.31}$ The "time domain" can be reduced to allow several hours of recording to be displayed on a single page or screen, as in the "compressed spectral array". ${ }^{32}$ This allows an assessment of amplitude and frequency 
Table: EEG Classification.*

\begin{tabular}{ll}
\hline Category & Subcategory \\
$\begin{array}{l}1 \text { Delta/theta }>50 \% \text { of record } \\
\text { (not theta coma) }\end{array}$ & A. Reactivity \\
& B. No reactivity
\end{tabular}

II Triphasic waves

III Burst-suppression

A. With epileptiform activity B. Without epileptiform activity

IV Alpha/theta/spindle coma (unreactive)

V Epileptiform activity

(not in burst-suppression pattern)

A. Generalized

B. Focal or multifocal

VI Suppression

A. $<20 \mu \mathrm{V}$, but $>10 \mu \mathrm{V}$

B. $\leq 10 \mu \mathrm{V}$

Suggested Guidelines for use of Table:

1. Burst-suppression pattern should have generalized flattening at standard sensitivity for $\geq$ I second at least every 20 seconds.

2. Suppression: for this category, voltage criteria should be met for the entire record; there should be no reactivity.

3. When $>1$ category applies, select the most critical:

- suppression is the most serious category

- burst-suppression is more important than the category of triphasic waves which is more significant than dysrhythmia or delta

- alpha pattern coma is more important than focal spikes, triphasic waves, dysrhythmia or delta categories.

* from ${ }^{37}$ with permission.

trends, variability, reactivity and the presence of sleep cycles. ${ }^{33}$ This can facilitate the recognition of seizures and evolutionary processes, such as the effects of an expanding hematoma. Compressed quantitative trending also provides important prognostic information (see "variability" discussed earlier.) By itself, however, spectral analysis may not demonstrate "nonstationarities" such as spikes, triphasic waves and some seizure patterns. Therefore, the "raw EEG" should also be available at all times. ${ }^{13}$

Short latency sensory evoked responses are characteristically preserved in reversible metabolic encephalopathies. However, in conditions that cause neuronal death, they are abnormal and can be prognostically very helpful. ${ }^{34}$ This applies especially to anoxic-ischemic encephalopathy in which absence of the N20 response with median nerve stimulation has a specificity and predictive value of $100 \%$ for an outcome no better than persistent vegetative state. ${ }^{35}$ The sensitivity for such outcome was, however, only $66 \%$; some patients with preservation of the N20 did not recover consciousness. Further refinements of the SEP, using amplitude criteria, may improve the sensitivity. The N70 potential may be more suitable, in that the specificity of an absent or grossly delayed response is much higher, while the specificity is also essentially $100 \% .{ }^{36}$ However, confirmatory studies with greater numbers of patients are needed. Such prognostically definitive tests are likely to be increasingly utilized in decision making in the intensive care unit.

\section{REFERENCES}

I. Glaser G. Metabolic, endocrine and toxic diseases. In: Remond A, ed. Handbook of Electroencephalography and Clinical Neurophysiology. Amsterdam: Elsevier 1972-1977; 15: 15C-3$15 \mathrm{C}-15$.
2. Creutzfeldt OD, Meisch JJ. Changes in cortical neuronal activity and EEG changes during hypoglycemia. In: Hernandez-Peon, E.. ed. The Physiological Basis of Mental Activity. Electroencephalogr Clin Neurophysiol 1963; Suppl 24: 158-171.

3. Young GB, Leung LS, Campbell V, et al. The electroencephalogram in metabolic/toxic coma. Am J EEG Technol 1992; 32: 243-259.

4. Hockaday JM, Potts F, Epstein C, Bonazzi A, Schwabb RS. Electroencephalographic changes in acute cerebral anoxia from cardiac or respiratory arrest. Electroencephalogr Clin Neurophysiol 1965; 18: 575-586.

5. Young GB, Bolton CF, Austin TW, Archibald Y, Wells GA. The encephalopathy associated with septic illness. Clin Investig Med 1990; 13: 297-304.

6. Hughes JR. Limitations of the EEG in coma and brain death. Ann NY Acad Sci 1978; 315: 121-136.

7. Paschen W, Bengtsson F, Rohn G, et al. Cerebral polyamine metabolism in reversible hypoglycemia in the rat: relation to energy metabolism and calcium. J Neurochem 1991; 57: 204 215.

8. Aoki Y, Lombroso CT. Prognostic value of electroencephalography in Reye's syndrome. Neurology 1973; 23: 333-343.

9. Yamada T, Young S, Kimura J. Significance of positive spike bursts in Reye syndrome. Arch Neurol 1977; 34: 376-380.

10. Stockard JJ, Bickford RG. The neurophysiology of anesthesia. $I n$ : Gordon E, ed. A Basis and Practice of Neuroanesthesia. II Amsterdam: Excerpta Medica 1975: 3-46.

11. Turrell RC, Roseman E. Electroencephalographic studies of the encephalopathies. IV. Serial studies in meningococcal meningitis. Arch Neurol Psychiatry 1955; 73: 141-148.

12. Vas GA, Cracco JB. Diffuse encephalopathies. $\ln$ : Daly DD. Pedley TA, eds. Current Practice of Clinical Electroencephalography. New York: Raven Press, 1990: 371-399.

13. Gloor P, Kalabay O, Giard, N. The electroencephalogram in diffuse encephalopathies. Brain 1968; 91: 779-802.

14. Illis LS, Taylor FM. The electroencephalogram in herpes simiplex encephalitis. Lancet 1972; 1: 718-721.

15. Gupta PC, Seth P. Periodic complexes in herpes simplex encephalitis. A clinical and experimental study. Electroencephalogr Clin Neurophysiol 1973; 35: 67-74.

16. Skoldenberg B, Forsgren M, Alestig K, et al. Acyclovir versus vidarabine in herpes simplex encephalitis. Lancet 1984; 2 : 707 711.

17. Young GB, Bolton CF, Austin TW, Archibald Y, Wells GA. The electroencephalogram in sepsis-associated encephalopathy. J Clin Neurophysiol 1992; 9: 145-152.

18. Fishgold $H$, Mathis P. Obnubilations Comas et stupeurs: etudes electroencephalographiques. Electroencephalogr Clin Neurophysiol 1959; Suppl 11: 27-68.

19. Karnaze DS, Bickford RG. Triphasic waves: a reassessment of their significance. Electroencephalogr Clin Neurophysiol 1984: 57 193-198.

20. Cant BR, Shaw NA, Monitoring by compressed spectral array in prolonged coma. Neurology 1984; 34: 35-39.

21. Sharbrough FW. EEG in different states of consciousness. purposeful responsiveness, including comatose and vegetative states. Presented at American EEG Society Meeting. June 9, 1981.

22. Young GB, Blume WT, Campbell VM, et al. Alpha, theta and alpha-theta coma: a clinical outcome study using serial recordings. Electroencephalogr Clin Neurophysiol 1994; 91: 92-99.

23. Synek VM. Validity of a revised EEG coma scale for predicting survival in anoxic encephalopathy. Clin Exp Neurol 1989; 26: 119-127.

24. Hockaday JM, Potts F, Epstein E, Bonazzi A, Schwabb RS. Electroencephalographic changes in acute cerebral anoxia from cardiac or respiratory arrest. Electroencephalogr Clin Neurophysiol 1965; 18: 575-586.

25. Rae-Grant AD, Barbour PJ, Reed J. Development of a novel EEG rating scale for head injury using dichotomous variables. J Clin Neurophysiol 1991; 79: 349-357. 
26. Hughes JR, Boshes B, Leesma J. Electroclinical and pathological correlations in comatose patients. Clin EEG 1976; 7: 13-30.

27. Synek VM. Prognostically important EEG coma patterns in diffuse anoxic and traumatic encephalopathies in adults. J Clin Neurophysiol 1988; 5: 161-174.

28. Aoki Y, Lombroso CT. Prognostic value of electroencephalography in Reye's syndrome. Neurology 1973; 23: 333-343.

29. Hansotia P, Gottschalk P, Green P, Zais D. Spindle coma: incidence, clinicopathological correlates and prognostic value. Neurology 1981; 31: 83-87.

30. Nuwer MR. Quantitative EEG: I. Techniques and problems of frequency analysis and topographic mapping. J Clin Neurophysiol 1988; 5: 1-43.

31. Nuwer MR. Quantitative EEG: II. Frequency analysis and topographic mapping in clinical settings. J Clin Neurophysiol 1988; 5: 45-85.
32. Bickford RG. Newer methods of recording and analyzing EEGs. $m$ : Klass DW, Daly DD, eds. Current Practice of Clinical Electroencephalography. New York: Raven Press, 1979: 451-480.

33. Chiappa KH, Hoch DB. Electrophysiologic monitoring. In: Ropper $\mathrm{AH}$, ed. Neurological and Neurosurgical Intensive Care. 3rd Edition. New York: Raven, 1993: 147-183.

34. Hill RA, Chiappa KH. Electrophysiological monitoring in the intensive care unit. Can J Neurol Sci 1994; 21: S12-S16.

35. Chen R, Bolton CF, Young GB. Prediction of outcome in patients with anoxic coma: a clinical and electroencephalograhic study. Crit Care Med 1996; 24: 672-678.

36. Madl C, Grim G, Kramer L, et al. Early prediction of individual outcome after cardiopulmonary resuscitation. Lancet 1993; 341 : 855-858.

37. Young GB, McLachlan RS, Kreeft JH, Demelo JD. An electroencephalographic classification for coma. Can J Neurol Sci, 1997; 24: 320-325. 